\title{
Boron Drug Delivery via Encapsulated Magnetic Nanocomposites: A New Approach for BNCT in Cancer Treatment
}

\author{
Yinghuai Zhu, ${ }^{1}$ Yongxiang Lin, ${ }^{1}$ Yi Zhun Zhu, ${ }^{2}$ Jia Lu, ${ }^{3}$ John A. Maguire, ${ }^{4}$ and \\ Narayan S. Hosmane ${ }^{5}$ \\ ${ }^{1}$ Institute of Chemical and Engineering Sciences, No. 1 Pesek Road, Jurong Island, Singapore 627833 \\ ${ }^{2}$ Department of Pharmacology, National University of Singapore, 18 Medical Drive, Kent Ridge, Singapore 117597 \\ ${ }^{3}$ Defence Medical \& Environmental Research Institute, DSO National Laboratories, 27 Medical Drive, Singapore 117510 \\ ${ }^{4}$ Department of Chemistry, Southern Methodist University, Dallas, TX 75275-0314, USA \\ ${ }^{5}$ Department of Chemistry and Biochemistry, Northern Illinois University, DeKalb, IL 60115-2862, USA
}

Correspondence should be addressed to Yinghuai Zhu, zhu_yinghuai@ices.a-star.edu.sg and

Narayan S. Hosmane, hosmane@niu.edu

Received 16 December 2009; Accepted 12 March 2010

Academic Editor: Ali Eftekhari

Copyright ( $) 2010$ Yinghuai Zhu et al. This is an open access article distributed under the Creative Commons Attribution License, which permits unrestricted use, distribution, and reproduction in any medium, provided the original work is properly cited.

\begin{abstract}
Ortho-carborane cages have been successfully attached to modified magnetic nanoparticles via catalytic azide-alkyne cycloadditions between 1-R-2-butyl-Ortho- $\mathrm{C}_{2} \mathrm{~B}_{10} \mathrm{H}_{10}(\mathrm{R}=\mathrm{Me}, 3 ; \mathrm{Ph}, 4)$ and propargyl group-enriched magnetic nanoparticles. A loading amount of $9.83 \mathrm{mmol}$ boron atom/g starch-matrixed magnetic nanoparticles has been reached. The resulting nanocomposites have been found to be highly tumor-targeted vehicles under the influence of an external magnetic field (1.14T), yielding a high boron concentration of $51.4 \mu \mathrm{g} / \mathrm{g}$ tumor and ratios of around $10: 1$ tumor to normal tissues.
\end{abstract}

\section{Introduction}

Boron Neutron Capture Therapy (BNCT) is potentially a promising and powerful binary anticancer therapy in which compounds containing the ${ }^{10} \mathrm{~B}$ isotope are selectively introduced into both dividing and nondividing tumor cells and then irradiated with thermal neutrons. The ${ }^{10} \mathrm{~B}$ nucleus adsorbs a neutron forming an excited ${ }^{11} \mathrm{~B}$ nucleus that undergoes a rapid fission reaction, producing a high-energy $\alpha$-particle $(1.47 \mathrm{MeV})$ and $\mathrm{Li}-7$ ion $(0.84 \mathrm{MeV})$, in addition to a low energy gamma $\gamma$ ray $(478 \mathrm{keV})$. These particles may cross a cell nucleus and thus destroy a tumor cell. The linear energy transfer (LET) of these heavily charged particles has a range of about one cell diameter $[1,2]$, which confines radiation damage to the cell from which they arise, hence minimizing cytotoxic effects on the surrounding tissue. Thus, if the boron can be selectively concentrated, the target region can be dosed with neutrons at a sizeable flux, but have minimal effect on the boron-free regions in the beam path. Boron-10 also has the advantages of being nonradioactive and easily incorporated into compounds. The required boron concentration is generally estimated at $10^{910} \mathrm{~B}$ atoms (natural abundance 19.9\%) per cell, which translates to approximately $35 \mu \mathrm{g}{ }^{10} \mathrm{~B}$ per gram of tissue [3]. To prevent damage to healthy tissue in the path of the neutron beam, the surrounding tissue should contain no more than $5 \mu \mathrm{g}$ of ${ }^{10} \mathrm{~B} / \mathrm{g}$ of tissue. A primary use of BNCT is in the treatment of malignant brain tumors, such as glioblastoma multiforme (GBM) [4]. This is one of the most malignant forms of cancer that infiltrates the brain so aggressively that surgery is rarely able to remove all of the cancerous tissue; it is virtually untreatable and is inevitably lethal $[5,6]$. In addition to treating difficult brain tumors, BNCT has been successfully employed in other cancer therapies. For example, a Finnish research group recently reported that a patient with recurrent head and neck tumors showed an excellent response to BNCT treatments [7]. Lung and liver tumors have also been investigated as potential candidates for BNCT [8, 9]. 


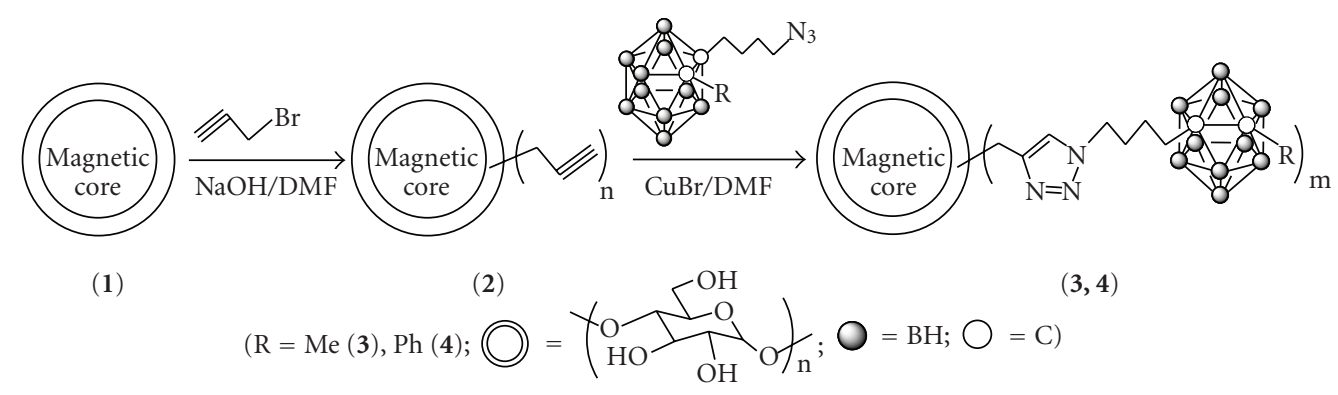

SCHEme 1: Synthesis of encapsulated magnetic nanocomposites.

Selective accumulation of boron in the tumor cells produces a substantial therapy ratio during BNCT. Consequently, improvements in boron delivery vehicles will dramatically improve BNCT effectiveness. However, in common with all other forms of chemotherapy, the "bottle-neck" obstacle to be overcome in BNCT is the relatively nonspecific in vivo distribution for most of the boron-containing compounds. When BNCT compounds are intravenously injected, they will generally distribute in both tumor and healthy cells, and methods must be developed to maximize the tumor/healthy tissue ratio. In the last decades, a variety of carrier molecules such as polyamines and liposomes have been investigated as possible boron delivery agents to tumor cells $[1,10-17]$. Despite these efforts, only two lowmolecular-weight compounds, $\mathrm{Na}_{2} \mathrm{~B}_{12} \mathrm{H}_{11} \mathrm{SH}$ (BSH) and 4borono- $L$-phenylalanine ( $L$-BPA) are currently in clinical trials. The results on these compounds are not universally promising, owing to their low tumor-to-blood and tumorto-brain tissue ${ }^{10} \mathrm{~B}$ ratios [10-17]. Hence, there is an urgent need for the development of potential precursor molecules and more sophisticated delivery systems in BNCT.

Magnetic nanoparticles (MNPs) have attracted attention because of their biological application in targeted drug delivery, thermotherapy, and as contrast enhancement in magnetic resonance imaging (MRI) [18-22]. Promising results have been achieved in a limited number of in vivo studies using functional MNPs as drug carriers [23-25]. In magnetically targeted therapy, a drug is attached to a biocompatible magnetic nanoparticle carrier such as a polymer-functionalized ferrofluid and is injected into the patient via the circulatory system. When these particles enter the blood stream, external, high-gradient magnetic fields can be used to concentrate the magnetic particles at a targeted site within the body. The concentrated drug can then be released via changes in physiological conditions or enzymatic activity followed by the tumor cell absorption [18]. A major advantage of this methodology exists in the decrease of the required amount of the cytotoxic drugs, thus reducing the associated side effects. This technique has been examined as a means to target cytotoxic drugs to brain tumors. Studies have demonstrated that particles as large as $1-2 \mu \mathrm{m}$ could be concentrated at the site of intracerebral rat glima-2 (RG-2) tumors; a later study demonstrated that $10-20 \mathrm{~nm}$ magnetic particles were even more effective in targeting these tumors in rats $[26,27]$. Studies of magnetic targeting in humans demonstrated that the infusion of ferrofluids is well tolerated in most of patients, and the ferrofluid could be successfully directed to advanced sarcomas without associated organ toxicity. In addition, it has been reported that a starchcovered magnetic nanoparticle $\left(\mathrm{Fe}_{3} \mathrm{O}_{4}\right)$ with a hydrodynamic diameter of $\sim 100 \mathrm{~nm}$ showed a significantly enhanced in vivo accumulation in gliosarcomas when directed by external magnets [28]. The nanoparticles persisted in the glioma for approximately 100 minutes after the removal of the external magnetic field [28], which, in the future, might be long enough for BNCT treatment. In addition, unlike other supported drugs, it is not necessary that the attached boron species be released from the particle supports for them to be effective. Application of this technique, therefore, can be considered appropriate for use in BNCT treatments. Herein, we report our preliminary results on the synthesis of encapsulated magnetic nanocomposites with a high load of carborane cages along with a preliminary study of their biodistrubutions.

\section{Results and Discussion}

Commercially available magnetic nanoparticles of iron oxides matrixed with starch have been enriched with the carborane cages, 1-R-2-butyl-ortho- $\mathrm{C}_{2} \mathrm{~B}_{10} \mathrm{H}_{10}(\mathrm{R}=\mathrm{Me}$, 3; $\mathrm{Ph}, 4)$, by catalytic azide-alkyne cycloaddition reactions. This reaction has been extensively developed and widely used in chemical transformations in biological applications and materials chemistry [29], such as cell surface labelling [30], biopolymers-viruses conjugation [31], and block copolymer synthesis [32]. In our case, starch modified magnetic nanoparticles were enriched with allyl-groups by reactions of free hydroxyl groups in starch with propargyl bromides in DMF in the presence of sodium hydroxides (Scheme 1). There were no significant changes in the IR spectra before and after immobilization of propargyl groups. However, after immobilizing the carborane cages, a new peak appeared at $v=2575 \mathrm{~cm}^{-1}$, assigned to the $\mathrm{B}-\mathrm{H}$ bond stretching (Figure 1). Compared with the starting compound 1Me-2- $\left(\mathrm{CH}_{2}\right)_{4} \mathrm{~N}_{3}-1,2-\mathrm{C}_{2} \mathrm{~B}_{10} \mathrm{H}_{10}$, the absorption of $\nu_{N \equiv N}$ at $2097 \mathrm{~cm}^{-1}$ disappeared in IR spectra of 3 (Figure 1). These results confirm the successful immobilization of propargyl and carborane groups. The successive attachments are consistent with the thermal gravimetric analysis (TGA) of 


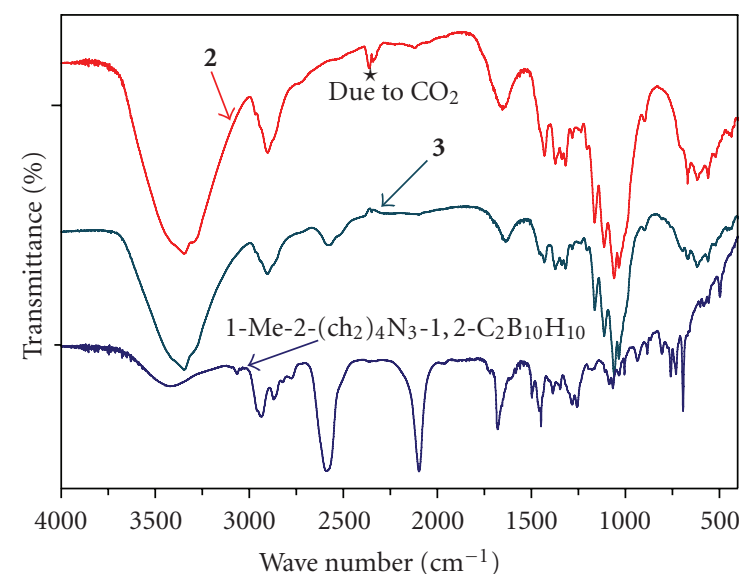

Figure 1: IR spectra of 1-Me-2- $\left(\mathrm{CH}_{2}\right)_{4} \mathrm{~N}_{3}-1,2-\mathrm{C}_{2} \mathrm{~B}_{10} \mathrm{H}_{10}, 2$, and 3.

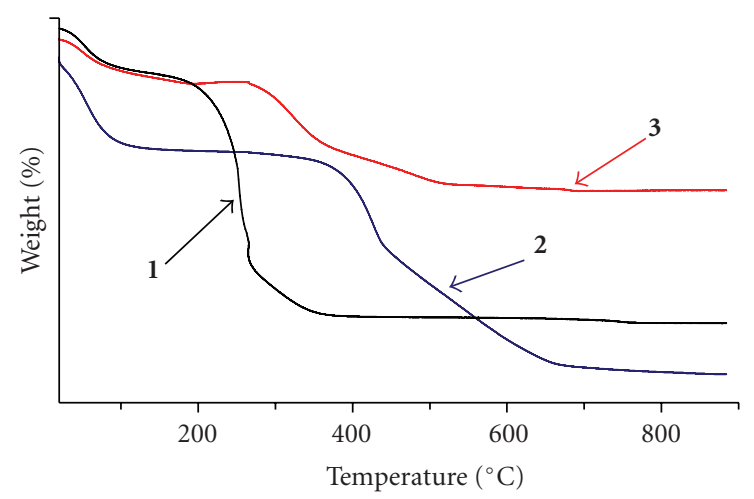

Figure 2: TGA curves of compound 1, 2 and 3 (not to scale),

compounds 1, 2, and 3, (Figure 2), the curves indicate a weight $\%$ loss of 27.7 and 33.2 for $\mathbf{1}$ and 2 , respectively, while compound 3 has a much smaller loss of $15.7 \%$. For the propargyl group, a loading amount of $1.40 \mathrm{mmol}$ per gram of starch-matrixed magnetic nanoparticles has been reached based on TGA and elemental analyses. Unfortunately, a lack of knowledge of the final TGA product of 3 prevented our determination of the loading amounts of carborane [33]. However, the ICP-OES analysis was decisive in obtaining a loading amount of $9.83 \mathrm{mmol}$ boron atom/g starch-matrixed magnetic nanoparticles.

It should be pointed out that, after modification, the TEM image of 3 (Figure 3(a)) showed that aggregation of the modified magnetic nanoparticles had occured, which may be caused by solvent evaporation of TEM samples. This phenomenon has been generally reported [34-36]. In contrast, most of the magnetic nanoparticles of $\mathbf{3}$ have been found separated in atomic force microscope (AFM) image (see Figures 3(d) and 3(e)).

Tissue distribution studies of 3 were conducted in a mixed solution of $\mathrm{DMSO} / \mathrm{saline}(\mathrm{v} / \mathrm{v}=1 / 10)$ in mice using a literature method [29]. We found that the modified nanoparticles were more stable in a mixed solution of DMSO/saline rather than in saline alone. DMSO may enhance nanoparticle dispersion in solution. Tissue boron concentrations at four time intervals of $8,16,30$, and 48 hours have been examined. The results are shown in Figures 4(a) and 4(b) in the absence and presence of an external magnet, respectively. From Figure 4(a), it can be seen that boron concentrations in different time intervals in the tumor are less than $14.7 \mu \mathrm{g} / \mathrm{g}$ tumor, with a slow elimination after 30 hours in the absence of an external magnetic field. The resulting boron concentration in tumor cells, shown in Figure 4(a), is lower than that found for the nido-carborane-appended water soluble single-wall carbon nanotubes, from which a maximum boron concentration of $22.8 \mu \mathrm{g}$ boron/g tumor was achieved at a 30-hour time point [33]. The lower accumulation in tumor cells of the magnetic nanoparticles may be caused by their low water solubility, compared with the water soluble nido-carborane-appended single-wall carbon nanotubes. In this regard, it should be pointed out that charge could be introduced in the boronated magnetic material, either by decapitation of the carborane or by the use of monoanionic monocarbaboranes. Figure 4(a) shows that, except for the brain, the ratios of boron concentrations of tumor to normal tissues are less than two. The low accumulation of boron in the brain might be due to the intact blood brain barrier (BBB). However, further studies are needed to confirm this hypothesis. Nonetheless, the results shown in Figure 4(a) do not satisfy the BNCT criteria [3]. The results exclude the feasibility of using magnetic nanocomposites as BNCT drug delivery vehicles in the absence of an external magnetic field. However, as shown in Figure 4(b), in the presence of an external magnetic field, the boron concentrations in tumor reached a high value of $51.4 \mu \mathrm{g} / \mathrm{g}$ tumor with tumor/normal tissue ratios of around $10: 1$. The high concentration sustained around 48 hours with a continuing external magnetic field is consistent with the literature data $[24,36]$. Since the entire tumor was resected and homogenized and then analyzed in our method, the obtained boron concentrations are average concentrations for the bulk tumor. The exact localization and status of the nanocomposites has not yet been determined. The nanomaterial could be either inside tumor interstitial or intracellular [36]. However, the TEM images (Figures 3(b) and 3(c)) have demonstrated that the entrapped magnetic nanocomposites aggregated inside the tumor, which is also consistent with the observations reported in the literature $[24,34,36]$. The exact mechanism of the accumulation of magnetic nanocomposite carriers in tumor cells has not been determined yet. Compared with the results without the external magnetic field, it is apparent that the introduction of an external magnetic field plays a key role in the enhanced accumulation of $c a 10$-fold higher nanoparticle concentrations entrapped within the tumor. In this regard, it should be pointed out that even the aggregated boron nanoparticles should be therapeutically effective for BNCT. However, further investigation is required to confirm the exact mechanism for the very high cellular uptake. In addition, based on previous reports [23], the magnetic nanocomposites used in this study are nontoxic and well tolerated in clinical trials after systemic administration. In addition, there was no evidence of tissue damage in any organs assayed in Figure 4, either in the presence or absence of the external magnetic field. Nonetheless, all these 


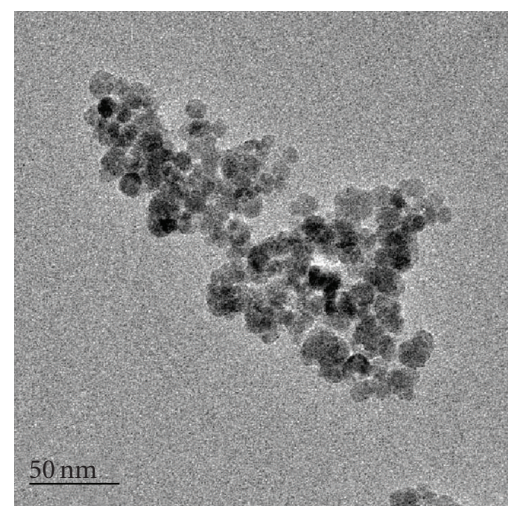

(a)

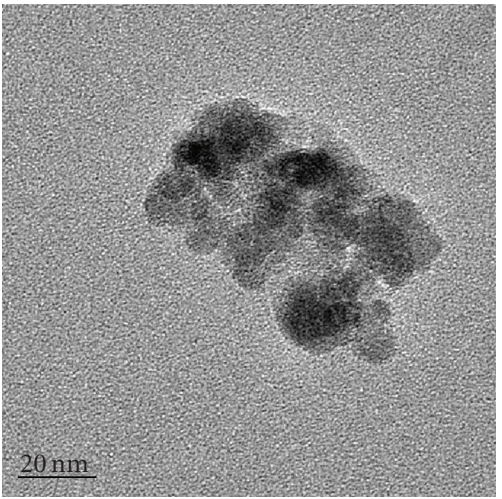

(c)

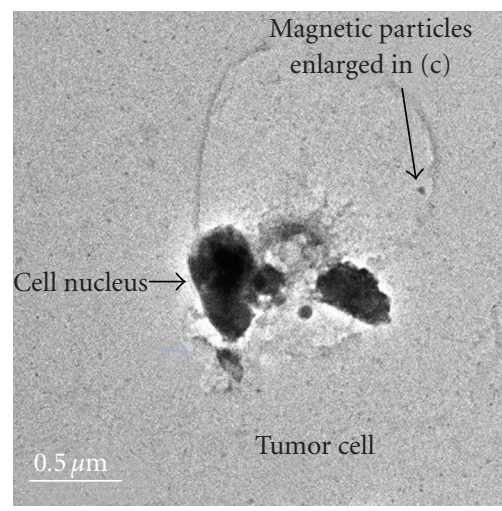

(b)

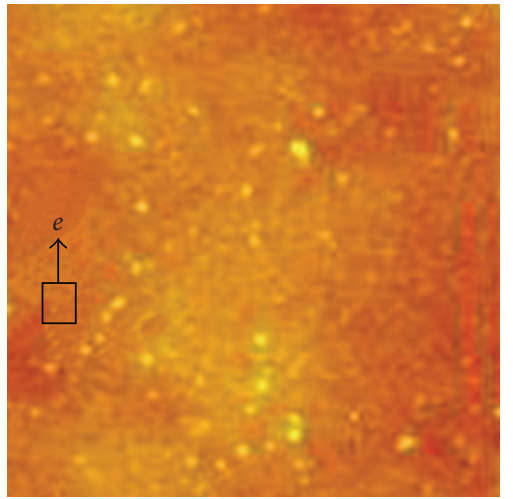

(d)

Section analysis

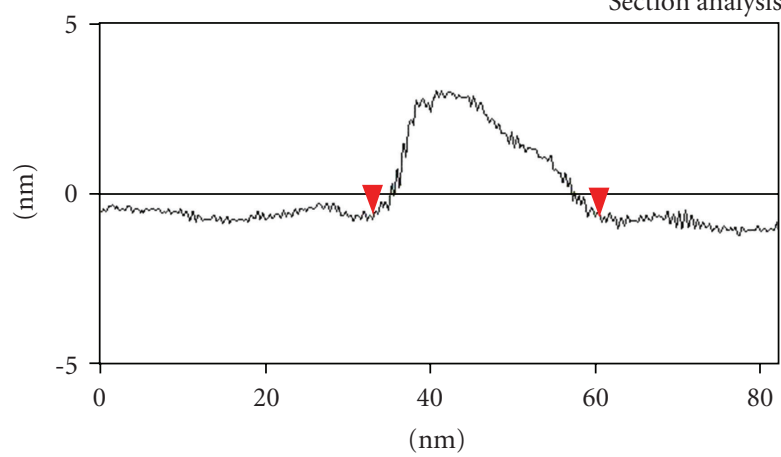

Spectrum
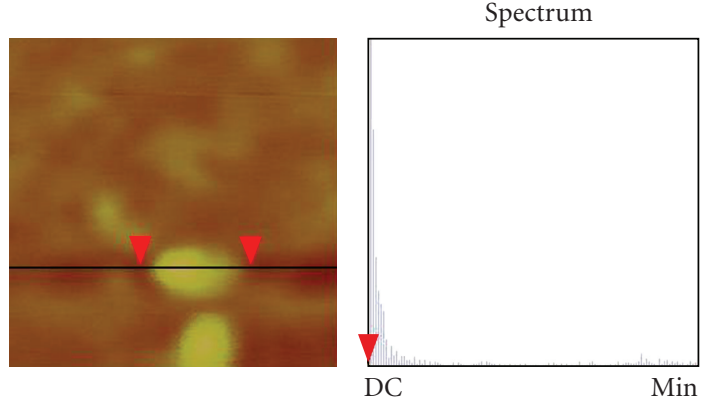

(e)

FIGURE 3: TEM images of the magnetic cores of compound 3; free (a), inside the tumor cells (b,c), AFM (d,e). 
promising results suggest that the delivery system can be potentially applied to the treatment of not only brain tumors, but also for other kinds of cancers through BNCT [8-21].

\section{Conclusions and Outlook}

Using "click" reaction, carborane cages have been successfully attached to modified magnetic nanoparticles for the first time. The resulting nanocomposites have been found to accumulate in tumor cells in high concentration in the presence of external magnetic field. These results provide new hope for the research of Neutron Capture Therapy (NCT) and the combination of the drugs with BNCT/MRI/Thermotherapy characteristics. More complete biodistribution and cytotoxicity studies are currently underway in our laboratories.

\section{Methods}

4.1. General Procedures and Materials. All operations were carried out under argon atmosphere in glove-box or using standard Schlenk lines. The purchased magnetic support $(50 \mathrm{mg} / \mathrm{ml}, 100 \mathrm{~nm}$, magnetic iron oxides matrixing with starch) was provided by chemicell GmbH. 1-Methyl- and 1-phenyl-closo-1,2- $\mathrm{C}_{2} \mathrm{~B}_{10} \mathrm{H}_{11}$ were obtained from Katchem Ltd. and used as received. Other reagents were supplied from Sigma-Aldrich Pte. Ltd., and used as received. 1-R2- $\left(\mathrm{CH}_{2}\right)_{4} \mathrm{~N}_{3}-1,2-\mathrm{C}_{2} \mathrm{~B}_{10} \mathrm{H}_{10}(\mathrm{R}=\mathrm{Me}, \mathrm{Ph})$ were prepared according to the literature procedures [33]. Dimethylformamide (DMF) was dried and then redistilled under reduced pressure before use. Infrared (IR) spectra were measured on a BIO-RAD spectrophotometer using $\mathrm{KBr}$ pellets. Elemental analyses were determined by a Perkin Elemer $2400 \mathrm{CHN}$ elemental analyzer. ICP analysis was determined using a VISTA-MPX, CCD Simultaneous ICP-OES analyzer. Thermogravimetric analyses (TGA) were carried out on a SDT 2960 Simultaneous DSC-TGA analyzer. Transmission Electron Microscopy (TEM) measurements were carried out on a JEOL Tecnai-G ${ }^{2}$, FEI analyzer operating at $200 \mathrm{kV}$. Atomic Force Microscope (AFM) was recorded on an OLYMPUS BX51M microscope.

4.2. Synthesis of Propargyl Groups-Enriched Magnetic Nanoparticles (2). A literature method was used to immobilize propargyl groups by the reaction of propargyl bromide with the hydroxyl groups on the starch matrix covering the surface of magnetic nanoparticles [37]. Under an argon atmosphere, with vigorous magnetic stirring, $10.0 \mathrm{~mL}$ (108.85 mmol, great excess) of propargyl bromide was slowly added to a solution of $200.0 \mathrm{mg}$ magnetic nanoparticles suspended in a mixed solvent of $30.0 \mathrm{~mL}$ of DMF and $5.0 \mathrm{~mL}$ of deionized water followed by the addition of $5.0 \mathrm{~g}$ of $\mathrm{NaOH}$. After stirring for 1 hour at room temperature, the reaction mixture was heated to $50^{\circ} \mathrm{C}$ for 2 days. The magnetic nanoparticles were collected with a magnet and washed with $2 \times 10.0 \mathrm{~mL}$ portions of diethyl ether to remove unreacted propargyl bromide. The magnetic material was then redispersed in $10.0 \mathrm{~mL}$ of deionized water,

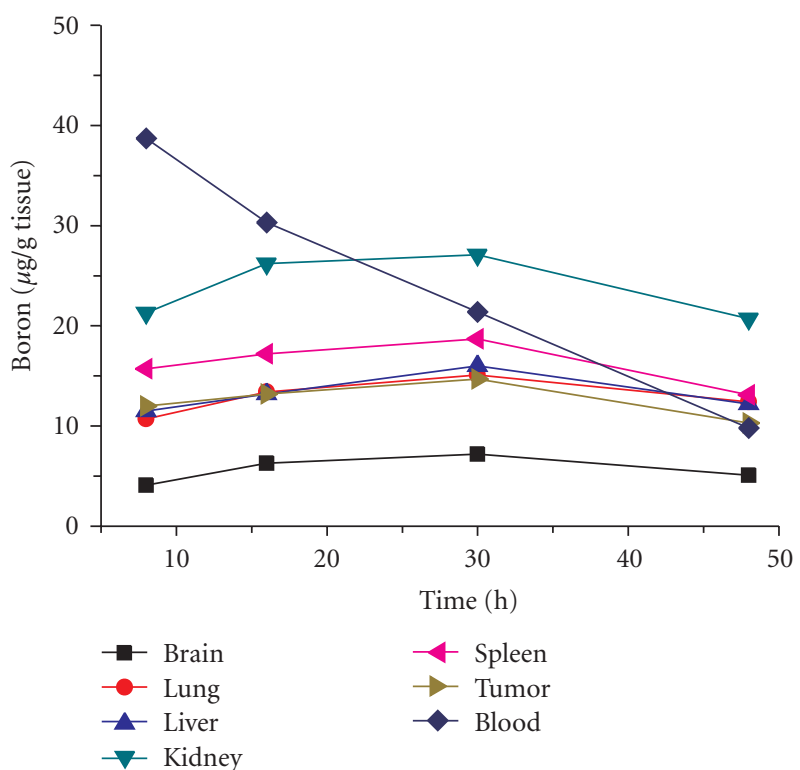

(a)

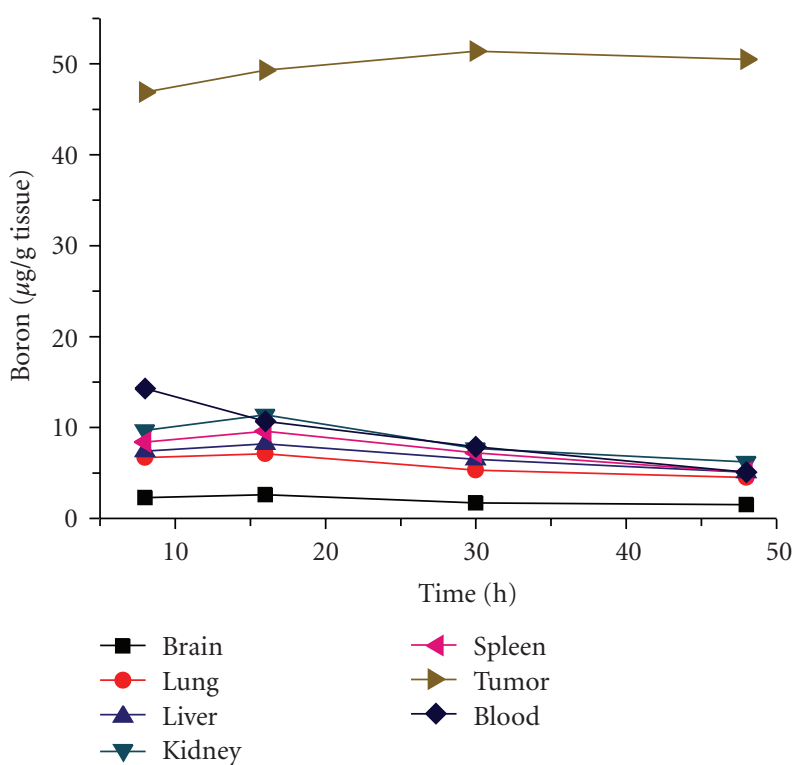

(b)

Figure 4: Boron tissue distribution of 3, (a) without external magnet, (b) with external magnet.

neutralized with $1 \mathrm{~N}$ aqueous $\mathrm{HCl}$ to $\mathrm{pH} \approx 6$, collected with a magnet, and washed with $2 \times 10.0 \mathrm{~mL}$ portions of oxygen-free, deionized water. Analyzed samples of magnetic nanoparticles, enriched with propargyl functional groups, were dried in high vacuum at $60^{\circ} \mathrm{C}$ for 3 days before subjecting them to analysis by elemental analysis (EA), IR spectra and TGA, respectively. A loading amount of $1.40 \mathrm{mmol}$ (propargyl group)/g (starch-matrixed magnetic nanoparticles) was obtained based on TGA and EA. IR ( $\mathrm{KBr}$ pellet, $\mathrm{cm}^{-1}$ ): 3345 (br, vs), 2902 (s, m), 1652 (s, m), 1430 (s, m), 1372 (s, m), 1317 (s, m), 1203 (s, m), 1163 (s, s), 1112 
(s, vs), 1060 (s, vs), 1034 (s, vs), 897 (s, m), 668 (s, m), 616 $(\mathrm{s}, \mathrm{m}), 559$ (s, m), and 435 (s, m).

4.3. Synthesis of 1-Me-1,2-closo- $\mathrm{C}_{2} \mathrm{~B}_{10} \mathrm{H}_{10-}$ Enriched Magnetic Nanoparticles (3). A literature method was modified to prepare compound $3[29,38]$. Under argon atmosphere, with continuous stirring, a $10.0 \mathrm{~mL}$ DMF solution $(50.0 \mathrm{mg} / \mathrm{mL})$ of the above prepared propargyl functional group-enhanced magnetic nanoparticles was added to DMF solution of $1.0 \mathrm{~g}$ (3.92 mmol) of 1-Me-2- $\left(\mathrm{CH}_{2}\right)_{4} \mathrm{~N}_{3}-1,2-\mathrm{C}_{2} \mathrm{~B}_{10} \mathrm{H}_{10}$ in $40.0 \mathrm{~mL}$ of DMF. $50.0 \mathrm{mg}(0.35 \mathrm{mmol}) \mathrm{CuBr}$ and $1.0 \mathrm{~mL}(4.70$ mmol) of $N, N, N^{\prime}, N^{\prime}, N^{\prime \prime}$-pentamethyldiethylenetriamine (PMDETA) were also added to above solution. The obtained solution was heated to $70^{\circ} \mathrm{C}$ for one week in dark. The reddish-brown magnetic particles were collected by magnet and washed with DMF $(2 \times 10.0 \mathrm{~mL})$ and deionized water $(2 \times 20.0 \mathrm{~mL})$ in sequence. Analyzed samples of magnetic nanocomposites, enriched with functionalized carborane cages, were dried in high vacuum at $60^{\circ} \mathrm{C}$ for 4 days before subjecting them to analysis by elemental analysis, ICP, TGA, IR, and TEM, respectively. A loading amount of $12.34 \mathrm{mmol}$ boron atom/g (starch-matrixed magnetic nanocomposites) was obtained based on ICP analysis. TEM samples were prepared as described in the literature [33]. In brief, one drop of a diluted solution of the carborane-enriched magnetic nanocomposite 3 was placed onto a copper grid coated with carbon followed by the solvent evaporation. AFM samples were also prepared according to literature [34]. Compound 3 was dispersed in deionized water using sonication for 30 minutes, a piece of clear silicon wafer was placed in the bottom of a beaker containing above mixture. The silicon wafer was kept in beaker for 2 hours to settle down dispersed nanoparticles. The silicon wafer was dried in vacuum for 20 hours before analysis. IR is $\left(\mathrm{KBr}\right.$ pellet, $\left.\mathrm{cm}^{-1}\right): 3344(\mathrm{br}$, vs), 2903 (s, m), 2575 (s, m), 1637 (s, m), 1430 (s, m), 1372 (s, m), 1318 (s, m), 1203 (s, m), 1162 (s, s), 1112 (s, vs), 1060 (s, vs), 1034 (s, vs), 897 (s, w), 694 (s, m), 618 (s, m), and 560 $(\mathrm{s}, \mathrm{m})$.

4.4. Synthesis of 1-Ph-1,2-closo- $\mathrm{C}_{2} B_{10} \mathrm{H}_{10}$-Enriched Magnetic Nanocomposite (4). In a method, similar to that employed above for 3, magnetic nanocomposite 4 was prepared from $1.0 \mathrm{~g}$ (3.2 mmol) of 1-Ph-2- $\left(\mathrm{CH}_{2}\right)_{4} \mathrm{~N}_{3}-1,2-\mathrm{C}_{2} \mathrm{~B}_{10} \mathrm{H}_{10}$ in $40.0 \mathrm{~mL}$ of DMF, $50.0 \mathrm{mg}(0.35 \mathrm{mmol}) \mathrm{CuBr}$, and $1.0 \mathrm{~mL}$ $(4.70 \mathrm{mmol})$ of PMDETA. A loading amount of $9.83 \mathrm{mmol}$ boron atom/g (starch-matrixed magnetic nanocomposites) was obtained based on ICP analysis. IR is ( $\mathrm{KBr}$ pellet, $\left.\mathrm{cm}^{-1}\right)$ : 3344 (br, vs), 2903 (s, m), 2583 (s, m), 1636 (s, m), 1456 (s, m), 1372 (s, m), 1317 (s, m), 1282 (s, m), 1204 (s, m), 1162 (s, s), 1112 (s, vs), 1059 (s, vs), 1034 (s, vs), 897 (s, m), 806.5 (s, w), 758 (s, m), 694 (s, m), 668 (s, m), 618 (s, m), 560 (s, $\mathrm{m})$, and 437 (s, m).

4.5. Evaluation of Biodistribution of (3). The biodistributions of compound 3 in a mixed solution of DMSO/saline $(\mathrm{v} / \mathrm{v}=1 / 10)$ were measured using 6-week-old female $\mathrm{BALB} / \mathrm{c}$ mice in a method similar to that reported in the literature [33]. The mice were housed and treated humanely under standard conditions. Breast tumor cells, BCAP-37 (MDA-MB-435i), and a mammary carcinoma were then transplanted into the right flank of the young female BALB/c mice of ca. 19-20 g body weight one week before testing. A $200 \mu \mathrm{L}$ of solution of $\mathbf{3}$ in a mixed solution of $\mathrm{DMSO} /$ saline $(\mathrm{v} / \mathrm{v}=1 / 10)$ at a concentration of $35 \mathrm{mg} / \mathrm{mL}$ was slowly injected into the tail vein of the mice. For magnetically directed drug studies, a block magnet $\left(20 \mathrm{~mm} \times 10 \mathrm{~mm} \times 5 \mathrm{~mm}\right.$, maximum $1.14 \mathrm{~T}$ at $\left.20^{\circ} \mathrm{C}\right)$ was bound just outside of the body close to tumors before drug injection. For comparison, seven tissues, tumor, blood, lung, liver, spleen, kidney, and brain samples were collected and analyzed with ICP-OES. The mice were anesthetized (diethyl ether) and bled into heparinized syringes via cardiac puncture before surgery to collect blood. The collected blood was then placed into tared cryogenic tubes and kept frozen at $-70^{\circ} \mathrm{C}$ for analysis. The mice were later sacrificed via cervical dislocation while anesthetized. Typical time course tissue distribution experiments examined the tissue boron concentration at four time intervals over 48 hours. The tumor and organ samples (liver, lung, spleen, kidney, brain and tumor) were collected, placed in tared cryogenic tubes, and kept frozen at $-70^{\circ} \mathrm{C}$ before being subjected to analysis with ICP-OES. Figure 4 shows the results of this study without and with external magnet, respectively. While each data point represents the average of five mice, for clarity, error bars are not shown in the graphical data; standard deviations were typically $\sim 5-15 \%$ of the average values. TEM samples were prepared by literature method [34, 39]. In brief, the tumors were fixed in a Karnovsky fixative of phosphate-buffered saline with $2 \%$ glutaraldehyde and $2.5 \%$ paraformaldehyde. The tumor samples were further cut into small pieces of $\sim 1 \mathrm{~mm}^{3}$, and post fixed with $2 \%$ osmium tetroxide fixative and $3 \%$ potassium ferricyanide for 1 hour. Then 1\% uranyl acetate was added for Enbloc staining overnight. The tumor samples were dehydrated using increasing concentrations of ethanol from $25 \%$ to $100 \%$. The dehydrated specimens were embedded in resin and dried at $\sim 50^{\circ} \mathrm{C}$ for 3 days in oven. The dry specimens were cut under a microscope, and the obtained thin slices were transferred onto copper TEM grids, followed by further staining in $1 \%$ osmium tetroxide for 3 minutes before subjected to TEM analysis.

A similar analysis using compound 4 was not possible due to its low water dispersibility.

\section{Acknowledgments}

This work was supported by the Institute of Chemical and Engineering Sciences (ICES) in Singapore. The authors are also grateful for the contributions made by their colleagues at ICES. NSH gratefully acknowledges the support from the National Science Foundation (CHE-0906179), Alexander von Humboldt Stiftung, and the NIU Inaugural Board of Trustees Professorship. JAM thanks the support from the Robert A. Welch Foundation (N-1322). They also thank Professor M. Frederick Hawthorne (University of MissouriColumbia) for his valuable comments and suggestions. 


\section{References}

[1] A. H. Soloway, W. Tjarks, B. A. Barnum, et al., "The chemistry of neutron capture therapy," Chemical Reviews, vol. 98, no. 4, pp. 1515-1562, 1998.

[2] M. F. Hawthorne, "The role of chemistry in the development of boron neutron capture therapy of cancer," Angewandte Chemie (International Edition in English), vol. 32, no. 7, pp. 950-984, 1993.

[3] R. G. Fairchild and V. P. Bond, "Current status of 10-B neutron capture therapy: enhancement of tumor dose via beam filtration and dose rate, and the effects of these parameters on minimum boron content: a theoretical evaluation," International Journal of Radiation Oncology Biology Physics, vol. 11, no. 4, pp. 831-840, 1985.

[4] E. R. Laws Jr. and M. E. Shaffrey, "The inherent invasiveness of cerebral gliomas: implications for clinical management," International Journal of Developmental Neuroscience, vol. 17, no. 5-6, pp. 413-420, 1999.

[5] R. F. Barth, J. A. Coderre, M. G. H. Vicente, and T. E. Blue, "Boron neutron capture therapy of cancer: current status and future prospects," Clinical Cancer Research, vol. 11, no. 11, pp. 3987-4002, 2005.

[6] A. Perry and R. E. Schmidt, "Cancer therapy-associated CNS neuropathology: an update and review of the literature," Acta Neuropathologica, vol. 111, no. 3, pp. 197-212, 2006.

[7] M. Kouri, L. Kankaanranta, T. Seppälä, et al., "Undifferentiated sinonasal carcinoma may respond to single-fraction boron neutron capture therapy," Radiotherapy and Oncology, vol. 72, no. 1, pp. 83-85, 2004.

[8] A. Wittig, M. Malago, L. Collette, et al., "Uptake of two ${ }^{10} \mathrm{~B}-$ compounds in liver metastases of colorectal adenocarcinoma for extracorporeal irradiation with boron neutron capture therapy (EORTC trial 11001)," International Journal of Cancer, vol. 122, no. 5, pp. 1164-1171, 2008.

[9] M. Suzuki, Y. Sakurai, S. Hagiwara, et al., "First attempt of boron neutron capture therapy (BNCT) for hepatocellular carcinoma," Japanese Journal of Clinical Oncology, vol. 37, no. 5, pp. 376-381, 2007.

[10] G. Wu, R. F. Barth, W. Yang, et al., "Boron containing macromolecules and nanovehicles as delivery agents for neutron capture therapy," Anti-Cancer Agents in Medicinal Chemistry, vol. 6, no. 2, pp. 167-184, 2006.

[11] R. Esfand and D. A. Tomalia, "Polyamidoamine (PAMAM) dendrimers: From biomimicry to drug delivery and biomedical applications," Drug Discovery Today, vol. 6, no. 8, pp. 427436, 2001.

[12] C. M. van Rij, A. J. Wilhelm, W. A. G. Sauerwein, and A. C. van Loenen, "Boron neutron capture therapy for glioblastoma multiforme," Pharmacy World and Science, vol. 27, no. 2, pp. 92-95, 2005.

[13] Y. Zhu, C. Y. Koh, J. A. Maguire, and N. S. Hosmane, "Recent developments in the boron neutron capture therapy (BNCT) driven by nanotechnology," Current Chemical Biology, vol. 1, pp. 141-149, 2007,.

[14] Z. J. Lesnikowski, E. Paradowska, A. B. Olejniczak, et al., "Towards new boron carriers for boron neutron capture therapy: metallacarboranes and their nucleoside conjugates," Bioorganic and Medicinal Chemistry, vol. 13, no. 13, pp. 41684175, 2005.

[15] M. W. Renner, M. Miura, M. W. Easson, and M. G. H. Vicente, "Recent progress in the syntheses and biological evaluation of boronated porphyrins for boron neutron-capture therapy,"
Anti-Cancer Agents in Medicinal Chemistry, vol. 6, no. 2, pp. 145-157, 2006.

[16] A. K. Azab, H. AbuAH, and M. Srebnik, "Boron neutron capture therapy," in Contemporary Aspects of Boron: Chemistry and Biological Applications, H. A. Ali, V Dembitsky, and M. Srebnik, Eds., chapter 5, pp. 338-366, Elsevier Science, Amsterdam, The Netherlands, 2005.

[17] R. F. Barth, J. A. Coderre, M. G. H. Vicente, T. E. Blue, and S.I. Miyatake, "Boron neutron capture therapy of brain tumors: current status and future prospects," in High-Grade Gliomas: Diagnosis and Treatment, G. Barnett, Ed., chapter 26, pp. 431461, Humana Press, Totowa, NJ, USA, 2007.

[18] C. Alexiou, W. Arnold, R. J. Klein, et al., "Locoregional cancer treatment with magnetic drug targeting," Cancer Research, vol. 60, no. 23, pp. 6641-6648, 2000.

[19] H. Lee, M. K. Yu, S. Park, et al., "Thermally cross-linked superparamagnetic iron oxide nanoparticles: synthesis and application as a dual imaging probe for cancer in vivo," Journal of the American Chemical Society, vol. 129, no. 42, pp. 1273912745, 2007.

[20] E. Allard, C. Passirani, and J.-P. Benoit, "Convection-enhanced delivery of nanocarriers for the treatment of brain tumors," Biomaterials, vol. 30, no. 12, pp. 2302-2318, 2009.

[21] O. V. Salata, "Applications of nanoparticles in biology and medicine," Journal of Nanobiotechnology, vol. 2, pp. 3-8, 2004.

[22] F. K. H. van Landeghem, K. Maier-Hauff, A. Jordan, et al., "Post-mortem studies in glioblastoma patients treated with thermotherapy using magnetic nanoparticles," Biomaterials, vol. 30, no. 1, pp. 52-57, 2009.

[23] A. S. Lübbe, C. Bergemann, H. Riess, et al., "Clinical experiences with magnetic drug targeting: a phase I study with 4'-epidoxorubicin in 14 patients with advanced solid tumors," Cancer Research, vol. 56, no. 20, pp. 4686-4693, 1996.

[24] S. K. Pulfer and J. M. Gallo, "Enhanced brain tumor selectivity of cationic magnetic polysaccharide microspheres," Journal of Drug Targeting, vol. 6, no. 3, pp. 215-227, 1998.

[25] C. Alexiou, R. Jurgons, R. J. Schmid, et al., "Magnetic drug targeting-biodistribution of the magnetic carrier and the chemotherapeutic agent mitoxantrone after locoregional cancer treatmen," Journal of Drug Targeting, vol. 11, pp. 139149, 2003.

[26] S. K. Pulfer, S. L. Ciccotto, and J. M. Gallo, "Distribution of small magnetic particles in brain tumor-bearing rats," Journal of Neuro-Oncology, vol. 41, no. 2, pp. 99-105, 1999.

[27] M. Sincai, D. Ganga, M. Ganga, D. Argherie, and D. Bica, "Antitumor effect of magnetite nanoparticles in cat mammary adenocarcinoma," Journal of Magnetism and Magnetic Materials, vol. 293, no. 1, pp. 438-441, 2005.

[28] B. Chertok, B. A. Moffat, A. E. David, et al., "Iron oxide nanoparticles as a drug delivery vehicle for MRI monitored magnetic targeting of brain tumors," Biomaterials, vol. 29, no. 4, pp. 487-496, 2008.

[29] H. C. Kolb, M. G. Finn, and K. B. Sharpless, "Click chemistry: diverse chemical function from a few good reactions," Angewandte Chemie (International Edition in English), vol. 40, no. 11, pp. 2004-2021, 2001.

[30] A. J. Link and D. A. Tirrell, "Cell surface labeling of Escherichia coli via copper(I)-catalyzed [3 + 2] cycloaddition," Journal of the American Chemical Society, vol. 125, no. 37, pp. 1116411165, 2003.

[31] S. S. Gupta, K. S. Raja, E. Kaltgrad, E. Strahle, and M. G. Finn, "Virus-glycopolymer conjugates by copper(I) catalysis 
of atom transfer radical polymerization and azide-alkyne cycloadditiont," Chemical Communications, no. 34, pp. 43154317, 2005.

[32] J. A. Opsteen and J. C. M. van Hest, "Modular synthesis of block copolymers via cycloaddition of terminal azide and alkyne functionalized polymers," Chemical Communications, no. 1, pp. 57-59, 2005.

[33] Z. Yinghuai, A. T. Peng, K. Carpenter, J. A. Maguire, N. S. Hosmane, and M. Takagaki, "Substituted carborane-appended water-soluble single-wall carbon nanotubes: new approach to boron neutron capture therapy drug delivery," Journal of the American Chemical Society, vol. 127, no. 27, pp. 9875-9880, 2005.

[34] J. Zhou, C. Leuschner, C. Kumar, J. F. Hormes, and W. O. Soboyejo, "Sub-cellular accumulation of magnetic nanoparticles in breast tumors and metastases," Biomaterials, vol. 27, no. 9, pp. 2001-2008, 2006.

[35] G. Beaune, B. Dubertret, O. Clément, C. Vayssettes, V. Cabuil, and C. Ménager, "Giant vesicles containing magnetic nanoparticles and quantum dots: feasibility and tracking by fiber confocal fluorescence microscopy," Angewandte Chemie (International ed. in English), vol. 46, no. 28, pp. 5421-5424, 2007.

[36] C. Bergemann, D. Muller-Schulte, J. Oster, L. Brassard, and A. S. Lübbe, "Magnetic ion-exchange nano- and microparticles for medical, biochemical and molecular biological applications," Journal of Magnetism and Magnetic Materials, vol. 194, no. 1, pp. 45-52, 1999.

[37] M. Touaibia, A. Wellens, T. C. Shiao, et al., "Mannosylated $\mathrm{G}(0)$ dendrimers with nanomolar affinities to Escherichia coli FimH," ChemMedChem, vol. 2, no. 8, pp. 1190-1201, 2007.

[38] C. N. Urbani, C. A. Bell, D. E. Lonsdale, M. R. Whittaker, and M. J. Monteiro, "Reactive alkyne and azide solid supports to increase purity of novel polymeric stars and dendrimers via the "click" reaction," Macromolecules, vol. 40, no. 19, pp. 70567059, 2007.

[39] S. C. Wuang, K. G. Neoh, E.-T. Kang, D. W. Pack, and D. E. Leckband, "HER-2-mediated endocytosis of magnetic nanospheres and the implications in cell targeting and particle magnetization," Biomaterials, vol. 29, no. 14, pp. 2270-2279, 2008. 

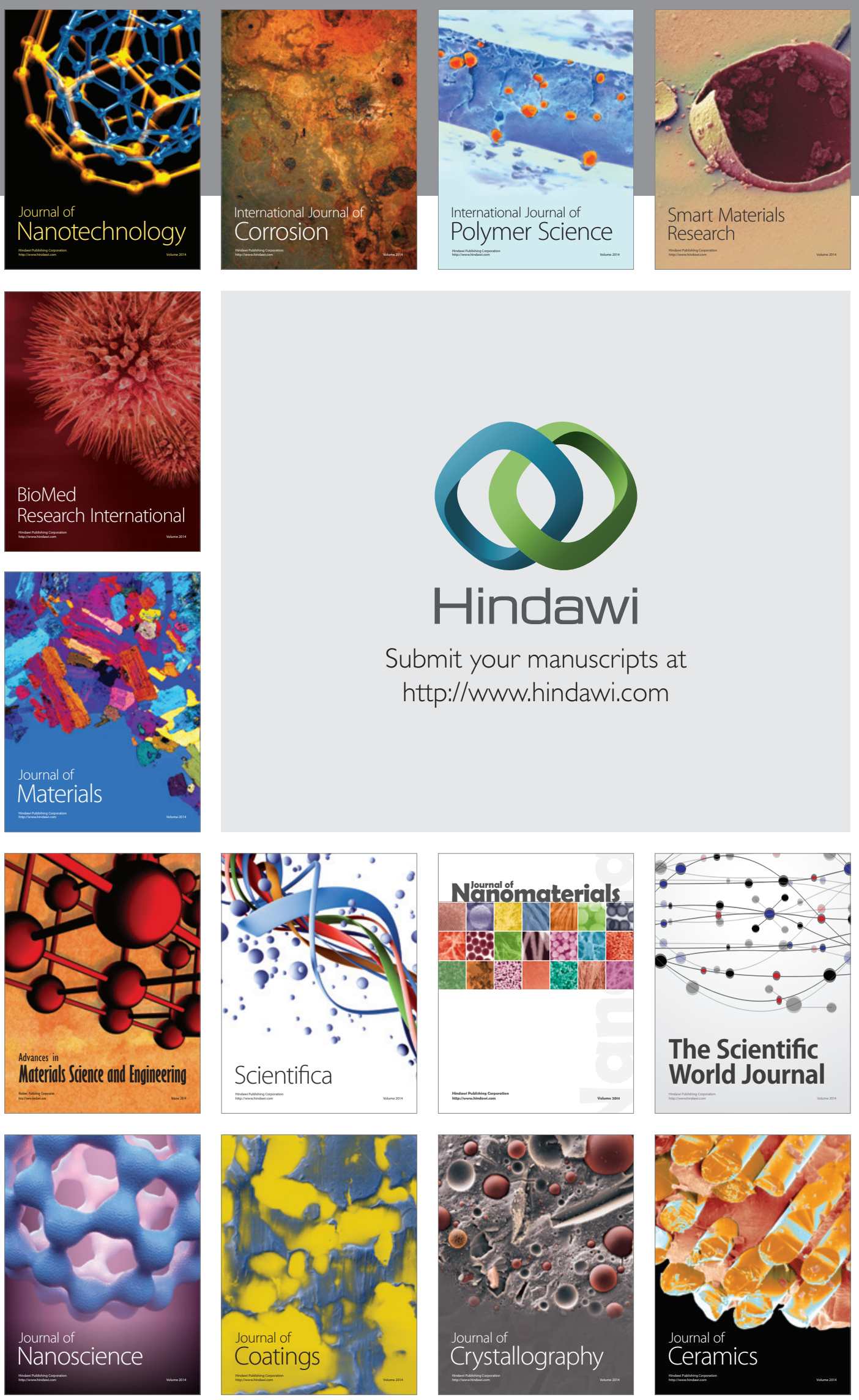

The Scientific World Journal

Submit your manuscripts at

http://www.hindawi.com

\section{World Journal}

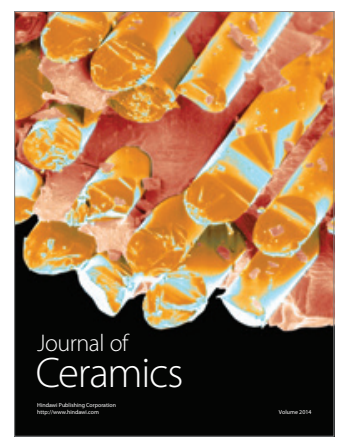

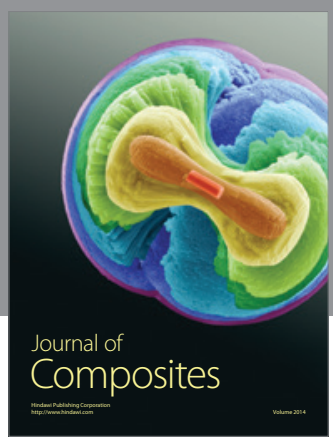
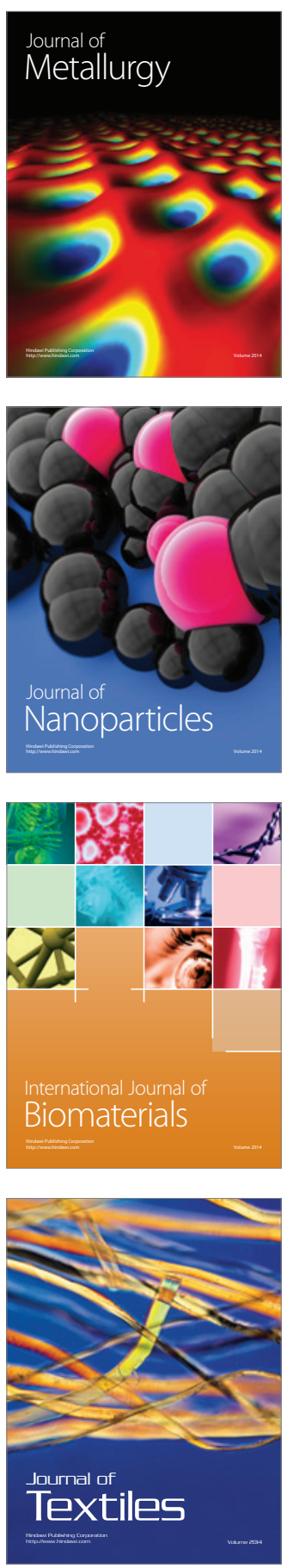